\title{
SOFT MAGNETIC MELT-SPUN RIBBONS FOR ENERGY AND SENSOR APPLICATIONS
}

\author{
Ivan ŠKORVÁNEK*, Jozef MARCIN*, Marek CAPIK*, Marek VARGA*, Jozef KOVÁČ ${ }^{*}$, Irena JANOTOVA**, \\ Peter ŠVEC $^{* *}$, Bogdan IDZIKOWSKI ${ }^{* * *}$ \\ ${ }^{*}$ Institute of Experimental Physics, Slovak Academy of Sciences, Watsonova 47, 04001 Košice, Slovak Republic, \\ e-mail: skorvi@saske.sk \\ ** Institute of Physics, Slovak Academy of Sciences, Dúbravská cesta 9, 84228 Bratislava, Slovak Republic \\ *** Institute of Molecular Physics PAS, Smoluchowskiego 17, 60-179 Poznań, Poland
}

\begin{abstract}
The continuing interest in development of new soft magnetic alloys is driven by industrial need to enhance the performance of electrical power generation/distribution devices and various energy conversion and sensor systems. In this work we report on development of Fe-Co-B-(P)-Cu melt-spun alloys with high magnetic flux density, where the beneficial effects of a heat treatment under magnetic field are discussed in terms of the improved magnetic softness and the possibility to tune the application-oriented properties. Soft magnetic FeNi- and FeCo-based amorphous and nanocrystalline alloys attract a considerable attention for various magnetic sensors. Examples of our recent work on the utilization of both longitudinal and transverse magnetic field annealing for tuning of giant magnetoimpedance (GMI) response in these alloys are briefly presented. The last part of this paper is devoted to search for magnetic materials with suitable magnetocaloric properties for magnetic refrigeration technology. We report on the beneficial effect of a partial cobalt substitution for iron on the magnetic entropy characteristics and the enhancement of refrigerant capacity in $\mathrm{GdFe}(\mathrm{Co}) \mathrm{Al}$-based alloys.
\end{abstract}

Keywords: soft magnetic materials, field annealing, magnetic sensors, giant magnetoimpedance, magnetic refrigeration

\section{INTRODUCTION}

Soft magnetic materials attract a great deal of current technological interest due to their applicability in various types of energy conversion and sensor devices. For example, the conversion of electrical energy into mechanical work and vice versa is done using electric motors and generators. Here, the magnetic materials have usually to retain their properties up to moderately high temperatures, which is demanding for most of the materials currently in use. Advanced soft magnetic materials are also of interest for inductors/transformers in high frequency power electronics components and power conditioning systems.

There are also new applications of magnetic materials which can help us reach larger energy efficiency. One of them is magnetic refrigeration, associated to the magnetocaloric effect (MCE), which is a basis of environmentally friendly refrigeration technology. Taking into account that the largest electricity consumption in the domestic market is related to refrigeration and air conditioning, the improvement of these devices is of high importance for potential energy savings.

This paper will focus on the optimization of magnetic properties in the series of Fe-Co-B-(P)-Cu melt-spun ribbons with high magnetic flux density, FeNi- and FeCobased amorphous and nanocrystalline alloys for GMI sensors as well as in the series of $\mathrm{GdFe}(\mathrm{Co}) \mathrm{Al}$-based alloys for magnetic refrigeration. An emphasis will be given on microstructure-property relationship in these alloys.

\section{SOFT MAGNETIC Fe-Co-B-(P)-Cu ALLOYS WITH HIGH MAGNETIC FLUX DENSITY}

Soft magnetic Fe-based nanocrystalline alloys produced by heat treatment of melt-spun amorphous ribbons are subject of systematic study over the past two decades. The important progress in this area has been recently reported by Ohta and Yoshizawa [1], [2] who developed a new series of Fe-B and Fe-Si-B base alloys with addition of small amount of $\mathrm{Cu}$, where the combined effect of an increased content of ferromagnetic elements and the small grain sizes after partial crystallization has lead to a marked enhancement of saturation magnetic induction while keeping relatively low values of coercive field. This development has brought renewed interest in the study of $\mathrm{Cu}$ addition on the crystallization behavior and magnetic properties of binary and ternary alloys originally designed as amorphous soft magnetic materials.

It is well known that a partial substitution of Co for Fe enhances the saturation magnetic induction in binary Fe-B amorphous alloys and leads to a better control of induced magnetic anisotropy and hysteresis loops shape upon magnetic field annealing [3]. Our aim in the present work is to explore the effects of $\mathrm{Co}$ and $\mathrm{Cu}$ addition on the microstructure and magnetic properties of thermally relaxed and partially crystallized Fe-Co-B-(P)-Cu amorphous alloys. Special focus has been given to the study of the influence of both longitudinal and transverse magnetic field applied during the heat treatment process on the soft magnetic properties. 


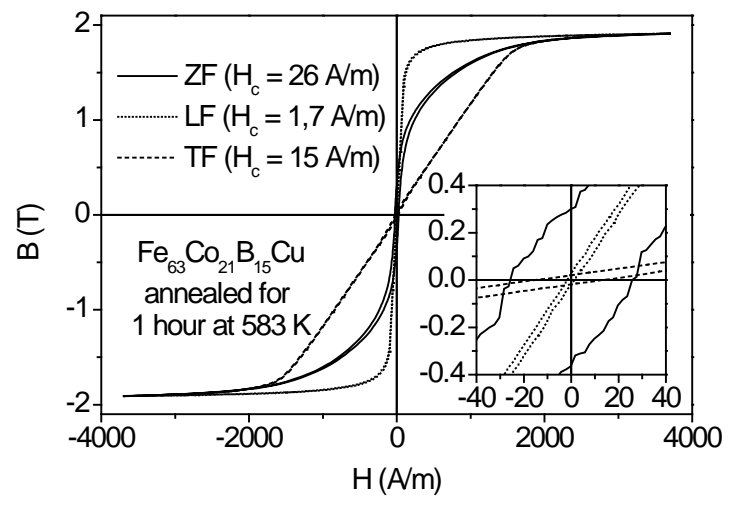

Fig. 1 Hysteresis loops for $\mathrm{Fe}_{63} \mathrm{Co}_{21} \mathrm{~B}_{15} \mathrm{Cu}$ after different field annealing for 1 hour at $583 \mathrm{~K}$, zero field annealing ( $\mathrm{ZF}$ ), longitudinal field annealing (LF) and transverse field annealing

Amorphous $\mathrm{Fe}_{63} \mathrm{Co}_{21} \mathrm{~B}_{15} \mathrm{Cu}$ and $\left(\mathrm{Fe}_{64} \mathrm{Co}_{21} \mathrm{~B}_{15}\right)_{96} \mathrm{P}_{3} \mathrm{Cu}_{1}$ ribbons were produced by planar flow casting. The samples with preferred direction of induced anisotropy were prepared by isothermal annealing in the presence of transverse (TF) or longitudinal (LF) magnetic field. In the case of TF-annealed samples, the furnace was placed inside the commercial permanent magnet system (Magnetic Solutions LTD) producing a magnetic field of $640 \mathrm{kA} / \mathrm{m}$. In the LF-annealed samples, the solenoidal coil that provided a magnetic field of $40 \mathrm{kA} / \mathrm{m}$ was used. The reference samples were annealed and cooled in a zero magnetic field (ZF).

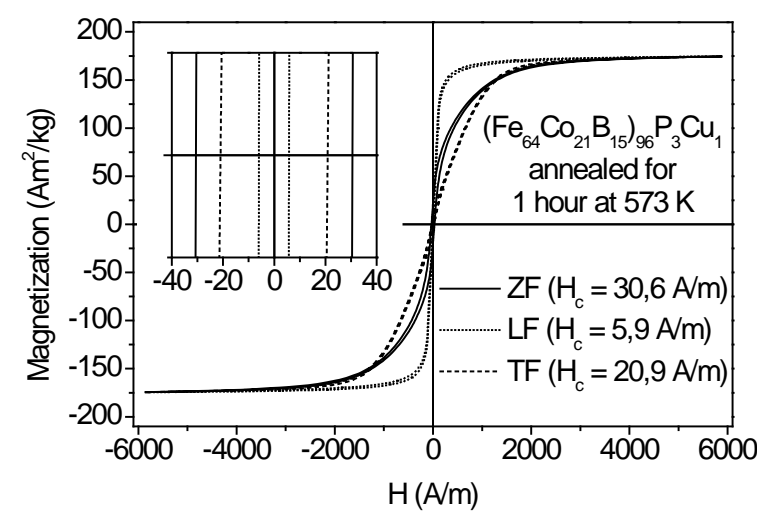

Fig. 2 Hysteresis loops for $\left(\mathrm{Fe}_{63} \mathrm{Co}_{21} \mathrm{~B}_{15}\right)_{96} \mathrm{P}_{3} \mathrm{Cu}_{1}$ after different field annealing for 1 hour at $573 \mathrm{~K}$, zero field annealing

(ZF), longitudinal field annealing (LF) and transverse field annealing (TF)

The effect of field annealing on the hysteresis loops of the differently heat treated $\mathrm{Fe}_{63} \mathrm{Co}_{21} \mathrm{~B}_{15} \mathrm{Cu}$ and $\left(\mathrm{Fe}_{64} \mathrm{Co}_{21} \mathrm{~B}_{15}\right)_{96} \mathrm{P}_{3} \mathrm{Cu}_{1}$ samples is demonstrated in Figs. 1 and 2 . We show that the specimens annealed without the presence of external magnetic field show the highest coercivity. Sheared loops with relatively good field linearity were achieved for all alloys after annealing in transverse magnetic field. A heat treatment under the presence of longitudinal magnetic field results in squared hysteresis loops characterized by very low coercive field values. The saturation magnetic flux density for the optimum field annealed amorphous $\mathrm{Fe}_{63} \mathrm{Co}_{21} \mathrm{~B}_{15} \mathrm{Cu}$ alloy reaches $1.83 \mathrm{~T}$ and the value of coercive field is $1.7 \mathrm{~A} / \mathrm{m}$. Such low $H_{c}$ values are superior to those previously reported for FeCo-based amorphous and nanocrystalline alloys [4] . In the case of $\left(\mathrm{Fe}_{64} \mathrm{Co}_{21} \mathrm{~B}_{15}\right)_{96} \mathrm{P}_{3} \mathrm{Cu}_{1}$ alloy the observed improvement of soft magnetic properties after LF annealing was found to be less significant. The high saturation magnetic flux density in combination with very low coercivity implies good prospects of these alloys for utilization in various energy conversion applications.

\section{TUNING OF GMI EFFECT BY FIELD ANNEALING IN FeNi- AND FeCo-BASED AMORPHOUS AND NANOCRYSTALLINE ALLOYS}

\subsection{Microstructure and magnetic properties}

In this work, we report on the effects of both longitudinal and transverse magnetic field applied during the heat treatment on the soft magnetic properties and giant magnetoimpedance effect (GMI) in series of amorphous and nanocrystalline $\left(\mathrm{Fe}_{0.5} \mathrm{Ni}_{0.5}\right)_{81} \mathrm{Nb}_{7} \mathrm{~B}_{12}$ and $\left(\mathrm{Fe}_{0.5} \mathrm{Co}_{0.5}\right)_{81} \mathrm{Nb}_{7} \mathrm{~B}_{12}$ ribbons prepared by planar flow casting.

The amorphous samples were isothermally annealed under a high vacuum at temperatures $623 \mathrm{~K} \leq \mathrm{T}_{\mathrm{a}} \leq 873 \mathrm{~K}$ in the presence of transverse (TF) or longitudinal (LF) magnetic field as well as in a zero magnetic field (ZF). The samples annealed at temperatures higher than $723 \mathrm{~K}$ undergo the transformation from amorphous to nanocrystalline structure. The TEM analysis of nanocrystalline samples annealed for 1 hour at $773 \mathrm{~K}$ (Fig. 3) has revealed a typical size of grains $5-10 \mathrm{~nm}$ for $\left(\mathrm{Fe}_{0.5} \mathrm{Co}_{0.5}\right)_{81} \mathrm{Nb}_{7} \mathrm{~B}_{12}$ alloy and 4-8 $\mathrm{nm}$ for $\left(\mathrm{Fe}_{0.5} \mathrm{Ni}_{0.5}\right)_{81} \mathrm{Nb}_{7} \mathrm{~B}_{12}$ alloy.
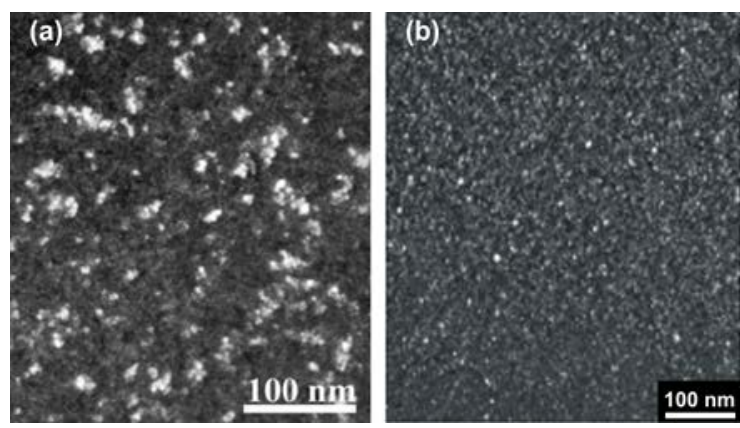

Fig. 3 TEM micrographs of nanocrystalline samples annealed at $773 \mathrm{~K}$. $\left(\mathrm{Fe}_{0.5} \mathrm{Co}_{0.5}\right)_{81} \mathrm{Nb}_{7} \mathrm{~B}_{12}$ (a) and $\left(\mathrm{Fe}_{0.5} \mathrm{Ni}_{0.5}\right)_{81} \mathrm{Nb}_{7} \mathrm{~B}_{12}$ (b)

The magnetic measurements showed an increase of coercive field after ZF-annealing, which was particularly significant in the case of $\left(\mathrm{Fe}_{0.5} \mathrm{Co}_{0.5}\right)_{81} \mathrm{Nb}_{7} \mathrm{~B}_{12}$ ribbon. On the other hand, a heat treatment under LF- and TFconditions resulted in a marked reduction of the coercivity in both FeCo- and FeNi-based samples. The lowest coercivity values were found for the thermally relaxed amorphous $\left(\mathrm{Fe}_{0.5} \mathrm{Ni}_{0.5}\right)_{81} \mathrm{Nb}_{7} \mathrm{~B}_{12}$ where $\mathrm{H}_{\mathrm{c}}$ reached $\sim 1 \mathrm{~A} / \mathrm{m}$ [5]. Sheared loops with good field linearity were achieved after TF-annealing. 


\subsection{Effect of field annealing on the giant magnetoimpedance effect}

The relative change of the impedance $(\mathrm{Z})$ with applied field $(\mathrm{H})$, which is defined as the giant magnetoimpedance effect [6] is expressed by

$\Delta Z / Z=\left(Z(H)-Z\left(H_{\max }\right) / Z\left(H_{\max }\right)\right) \times 100 \%$,

where $H_{\max }$ is the maximum field used $(10 \mathrm{kA} / \mathrm{m}$ in our case). The high sensitivity of $\Delta \mathrm{Z} / \mathrm{Z}$ ratio to external static magnetic field in soft magnetic ribbons and wires makes them attractive materials for magnetic sensor applications. GMI sensitivity is defined as the derivative of the GMI ratio with respect to the external DC magnetic field as given by equation (2).

$\eta=d(\Delta Z / Z) / d H$

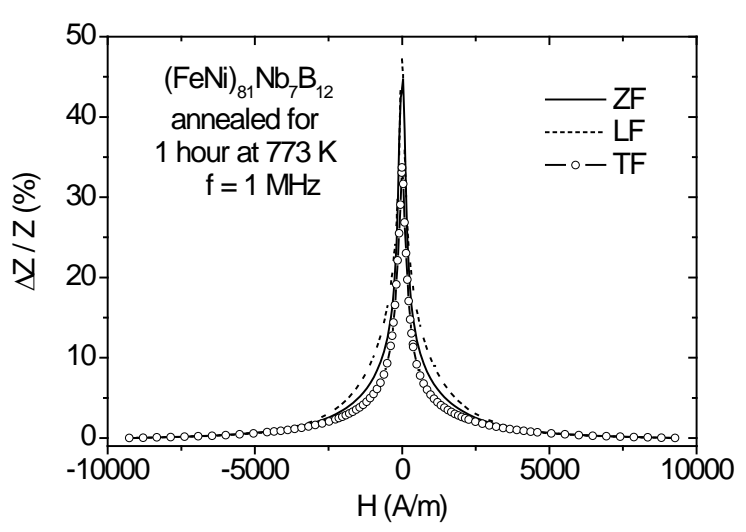

Fig. 4 Magnetic field dependence of GMI ratio $\Delta \mathrm{Z} / \mathrm{Z}$ after different field annealing for nanocrystalline $\left(\mathrm{Fe}_{0.5} \mathrm{Ni}_{0.5}\right)_{81} \mathrm{Nb}_{7} \mathrm{~B}_{12}$

The GMI measurements were performed over a frequency range $0.1-10 \mathrm{MHz}$. The field annealing has resulted in the modified GMI characteristics of both amorphous and nanocrystalline ribbons. The $\left(\mathrm{Fe}_{0.5} \mathrm{Ni}_{0.5}\right)_{81} \mathrm{Nb}_{7} \mathrm{~B}_{12}$ samples in nanocrystalline state exhibited larger values of GMI ratio $(\Delta \mathrm{Z} / \mathrm{Z})$ as compared to their amorphous counterparts. Fig. 4 shows that the maximum $\Delta \mathrm{Z} / \mathrm{Z}$ values for nanocrystalline $\left(\mathrm{Fe}_{0.5} \mathrm{Ni}_{0.5}\right)_{81} \mathrm{Nb}_{7} \mathrm{~B}_{12}$ alloy annealed at $773 \mathrm{~K}$ for 1 hour are observed after longitudinal field annealing. The GMI field sensitivity for this sample reached at frequency 1 $\mathrm{MHz}$ the maximum value $\eta_{\max } \sim 12 \% / \mathrm{Oe}$.

On the other hand, the $\left(\mathrm{Fe}_{0.5} \mathrm{Co}_{0.5}\right)_{81} \mathrm{Nb}_{7} \mathrm{~B}_{12}$ ribbons exhibit the highest values of GMI ratio $\Delta \mathrm{Z} / \mathrm{Z}$ in a thermally relaxed amorphous state. Here after transverse field annealing at $623 \mathrm{~K}$ for 1 hour the $\Delta \mathrm{Z} / \mathrm{Z}$ reaches $\sim 27$ $\%$ (see Fig. 5). The GMI field sensitivity for this sample reached at frequency $5 \mathrm{MHz}$ the maximum value $\eta_{\max }$ $\sim 3.7 \% /$ Oe. For this alloy, the GMI response exhibits single or double peak structure depending on the orientation of external magnetic field applied during the heat treatment. The position of peaks at GMI curve correspond to an effective magnetic anisotropy field induced during the field annealing [6].

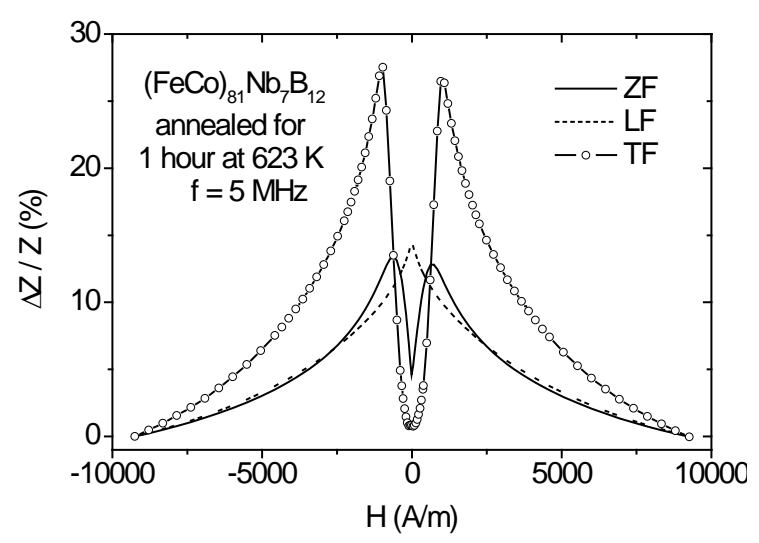

Fig. 5 Magnetic field dependence of GMI ratio $\Delta \mathrm{Z} / \mathrm{Z}$ after different field annealing for amorphous $\left(\mathrm{Fe}_{0.5} \mathrm{Co}_{0.5}\right)_{81} \mathrm{Nb}_{7} \mathrm{~B}_{12}$

\section{MAGNETOCALORIC PROPERTIES IN GdFe(Co)Al-BASED MELT-SPUN RIBBONS}

Among the recently developed magnetic refrigerant materials, the GdFeAl-based glassy alloys prepared by melt-spinning combine favourable magnetic entropy characteristics with sufficiently high effective magnetic moment per volume, which makes them good candidates for magnetic refrigeration in a wide operating temperature range $[7,8]$.

In this work, we report on beneficial effect of partial Co substitution for $\mathrm{Fe}$ on magnetocaloric properties of melt-spun $\mathrm{Gd}_{65} \mathrm{Fe}_{20-\mathrm{y}} \mathrm{Co}_{\mathrm{y}} \mathrm{Al}_{10} \mathrm{~B}_{5}$ alloys. Typical microstructure of the $\mathrm{Gd}_{65} \mathrm{Fe}_{20} \mathrm{Al}_{10} \mathrm{~B}_{5}$ ribbon in the asquenched state is shown in Fig. 6. Here, few $\mathrm{Gd}$ nanocrystalline particles embedded in surrounding amorphous matrix were detected similarly as observed recently in [7] for the similar composition alloy.

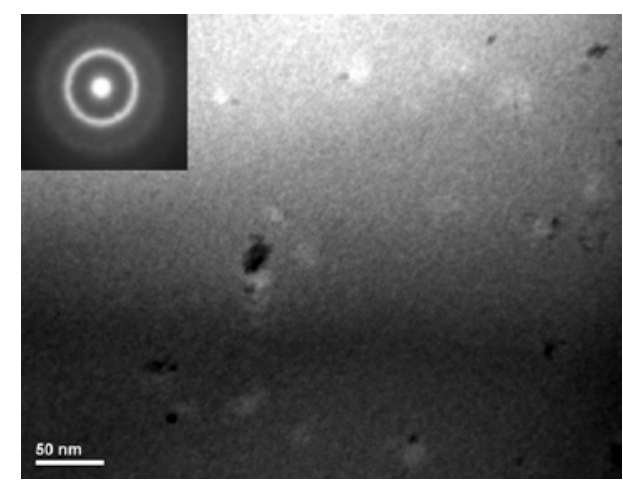

Fig. 6 TEM micrograph of $\mathrm{Gd}_{65} \mathrm{Fe}_{20} \mathrm{Al}_{10} \mathrm{~B}_{5}$ melt-spun ribbon in the as-quenched state

The magnetic entropy changes, $\left|\Delta \mathrm{S}_{\mathrm{M}}\right|$, were calculated from the magnetization versus applied field dependences measured by SQUID magnetometer. Fig. 7 shows an example of the set of isothermal magnetization curves measured in applied magnetic field up to $5 \mathrm{~T}$ at different temperatures ranging from 5 to $250 \mathrm{~K}$. 


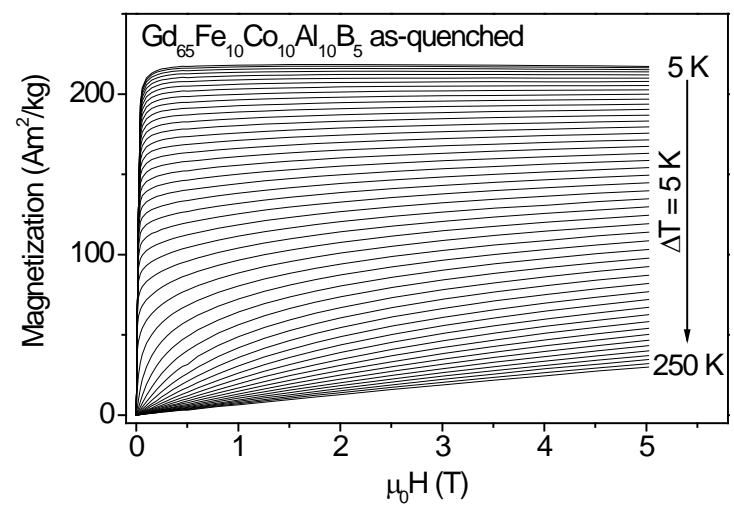

Fig. 7 Field dependences of the magnetization measured at $5 \mathrm{~K}$ steps

Fig. 8 shows that the value of the maximum magnetic entropy change in our Co-substituted $\mathrm{Gd}_{65} \mathrm{Fe}_{10} \mathrm{Co}_{10} \mathrm{Al}_{10} \mathrm{~B}_{5}$ ribbon after the magnetic field change from 0 to $5 \mathrm{~T}$ reaches $\left|\Delta \mathrm{S}_{\mathrm{M}}\right|=7.02 \mathrm{~J} / \mathrm{kgK}$ at $150 \mathrm{~K}$. This $\left|\Delta \mathrm{S}_{\mathrm{M}}\right|$ value is higher than that reported for its Co-free $\mathrm{Gd}_{65} \mathrm{Fe}_{20} \mathrm{Al}_{10} \mathrm{~B}_{5}$ counterpart, where the $\left|\Delta \mathrm{S}_{\mathrm{M}}\right|$ reached under the same conditions only $5.17 \mathrm{~J} / \mathrm{kgK}$.

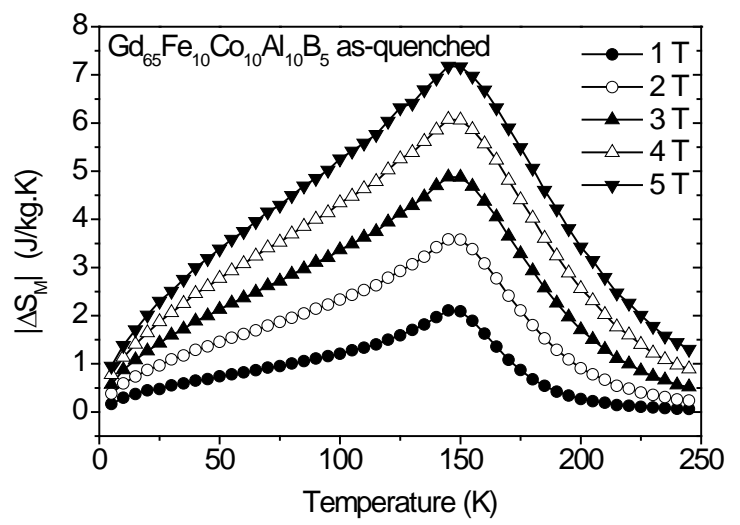

Fig. 8 The magnetic entropy changes $\left|\Delta S_{M}\right|$ vs. temperature $\mathrm{T}$ calculated for different changes of external magnetic field $\Delta \mathrm{H}$ up to $5 \mathrm{~T}$

The values of refrigeration capacity, RC, were determined as the area below the $\left|\Delta \mathrm{S}_{\mathrm{M}}\right|$ peak with the integration limits corresponding to the temperatures at its half maximum. The RC value at $5 \mathrm{~T}$ for $\mathrm{Gd}_{65} \mathrm{Fe}_{10} \mathrm{Co}_{10} \mathrm{Al}_{10} \mathrm{~B}_{5}$ ribbon was calculated to be $766 \mathrm{~J} / \mathrm{kg}$, which is also higher that that reported for the Co-free alloy. The enhanced values of magnetic entropy changes and the high refrigeration capacity together with the good magnetic softness leading to the low hysteresis losses make these Co-substituted glassy alloys promising magnetic refrigerants in temperature range of $80-180 \mathrm{~K}$. A shift the operating temperatures toward the higher temperature range and the further enhancement of refrigerant capacity can be attained using multiphase composites that are formed by a heat treatment of meltspun GdFeAl-based ribbons leading to a formation of different amount of crystalline particles in the residual amorphous matrix [9]. The "table-like” MCE makes such composites promising magnetic refrigerants below the room temperature.

\section{ACKNOWLEDGMENTS}

This work was performed within the frame of the project "New materials and technologies for energetics“" ITMS: 26220220061, which is supported by the Operational Program "Research and Development" financed through European Regional Development Fund. The partial support of VEGA 2/0209/10, APVV-0492-11 and APVV-0266-10 is also acknowledged.

\section{REFERENCES}

[1] OHTA, M. - YOSHIZAWA, Y.: Mater. Transactions, vol. 48, (2007), 2378-2380.

[2] OHTA, M. - YOSHIZAWA, Y.: J. Appl. Phys., vol. 103, (2008) 07E722.

[3] O`HANDLEY, R. C.: Modern Magnetic Materials : Principles and Applications, JOHN WILEY \& SONS, Inc., New York, 1999.

[4] ŠKORVÁNEK, I. - MARCIN, J. - KRENICKÝ, T. - KOVÁČ, J. - ŠVEC, P. - JANIČKOVIČ, D.: J. Magn. Magn. Mater., vol. 304, (2006), 203.

[5] TURČANOVÁ, J. - MARCIN, J. - KOVÁČ, J. JANIČKOVIČ, D. - ŠVEC, P. - ŠKORVÁNEK, I.: Journal of Physics: Conference Series, Vol. 144, (2009), 012065 1-4.

[6] MAHN - HUONG, P. - HUA - XIN, P.: Progress in Materials Science. vol. 53 (2008), 323-420.

[7] GORSSE, S. -CHEVALIER, B. - ORVEILLON, G.: Appl. Phys. Lett. vol. 92 (2008), 122501.

[8] FANG, Y. K. -LAI, C. H. - HSIEH, C. C. - ZHAO, X. G. - CHANG, H. W. - CHANG, W. C. - LI, W: J. Appl. Phys. vol. 107 (2010), 09A901.

[9] ŠKORVÁNEK, I. - MARCIN, J. - KOVÁČ, J. ŚNIADECKI, Z. - IDZIKOWSKI, B. - ŠVEC, P.: JEMS2012, Parma, Italy, Sept. 9 - 14, 2012, Book of Abstracts, p. 386.

Received February 10, 2013 , accepted February 15, 2013

\section{BIOGRAPHY}

Jozef Kováč was born in 1954. In 1977 he graduated from the Faculty of Science, P. J. Šafárik University in Košice. He defended his CSc in 1989. Since 1977 he has been working at Institute of Experimental Physics Slovak Academy of Sciences, now as senior researcher in the Laboratory of Nanomaterials and Applied Magnetism. His research area is the study of magnetic properties of amorphous and nanocrystalline materials and nanoparticles. 